\title{
Brand Loyalty Gain or Loss? Effects of Mobile App Gamification for Retailers: An Abstract
}

\author{
Ines Hackeradt and Waldemar Toporowski
}

\begin{abstract}
The smartphone is a permanent companion for shopping trips and also crucial for product research at POS or at home. Necessarily, either online or traditional store retailers have to reconsider their mobile appearance and adjust it to their consumers' new shopping behavior. The use of game-like elements is called gamification and has the aim to raise emotions such as fun and happiness, which lead to a positive app experience and therefore consumers are more willing to accept and use the app. Normative beliefs encourage social value of an app and consumers want to compete in the games with friends. Through positive app experience, the attitude towards the retailer improves, recommendations are forwarded to social networks like Twitter or Facebook, and loyalty towards the retailer is built. Our aim is to analyze emotional and social values in retailing apps which use gamified elements to show the effect of emotional and social values on app loyalty and brand loyalty. Our contribution is to give retailers and marketers more insights about the possible brand loyalty enhancement or decline to which gamification in mobile apps can lead.
\end{abstract}

I. Hackeradt $(\bowtie) \bullet$ W. Toporowski

Georg-August-Universität Göttingen, Göttingen, Germany

e-mail: ihacker@uni-goettingen.de; wtoporo@uni-goettingen.de 